\title{
Oral or intravenous vinorelbine plus capecitabine in heavily pretreated HER2 negative metastatic breast cancer; similar effect or quality of life?
}

\author{
Kadri Altundag ${ }^{1}$ (D)
}

Received: 24 March 2019 / Accepted: 30 March 2019 / Published online: 23 April 2019

(c) Springer Science+Business Media, LLC, part of Springer Nature 2019

\section{Dear Editor,}

I want to congratulate Torres and their colleagues [1] in which they investigated evaluated the efficacy and safety of the Vinorelbine/Capecitabine doublet (VINOCAP) in heavily pretreated HER2 negative metastatic breast cancer (MBC) patients with vinorelbine $22.5 \mathrm{mg} / \mathrm{m} 2 \mathrm{IV}$ on days 1 and 8 combined with capecitabine $1 \mathrm{~g}$ PO BID for 14 consecutive days of 21 day cycles. They concluded that VINOCAP appears to be an active and well-tolerated regimen in women with MBC, particularly as fourth or greater line of chemotherapy. Authors cited phase I and phase II clinical trials that used the combination of intravenous vinorelbine and capecitabine. Of note, among these, one study used oral vinorelbine instead of IV vinorelbine combined with capecitabine [2]. Furthermore, for many patients especially receiving third or fourth line chemotherapy, an active alloral combination chemotherapy regimen that avoids the need for intravenous treatment administration visits at the clinic might be preferable [3]. The results of two consecutive phase II studies may suggest that oral and iv vinorelbine, in combination with capecitabine, can achieve similar responses in patients with $\mathrm{MBC}$ refractory to anthra-taxane combinations [4]. Taken all together all-oral combination regimen such as oral vinorelbine plus capecitabine might be offered as an alternative to VINOCAP, particularly if patients wish to avoid frequent clinic visits for intravenous therapy administration.

This comment refers to the article available at https://doi. org/10.1007/s10549-019-05203-1.

Kadri Altundag

altundag66@yahoo.com

1 MKA Breast Cancer Clinic, Tepe Prime, 06800 Cankaya, Ankara, Turkey
Funding Author has not received any grants.

\section{Compliance with ethical standards}

Conflict of interest I have no conflict of interest to declare.

Ethical approval The manuscript complies with the Ethical Rules applicable for this journal.

Research involving human and animal rights This article does not contain any studies with human participants or animals performed by any of the authors.

\section{References}

1. Torres A, Ramdial JL, Aguirre LE, Mahtani R, Vogel CL (2019) Vinorelbine plus Capecitabine (Vinocap): a retrospective analysis in heavily pretreated HER2 negative metastatic breast cancer patients. Breast Cancer Res Treat 25:236. https://doi.org/10.1007/ s10549-019-05203-1

2. Lorusso V et al (2006) Oral vinorelbine plus capecitabine (oral vincap) combination in patients with advanced breast cancer (ABC). A phase II study of the GOIM (Gruppo Oncologico dell'Italia Meridionale). Ann Oncol 17(Suppl 7):vii15-vii17

3. Cinieri S, Chan A, Altundag K (2017) Final results of the randomized phase II NorCap-CA223 trial comparing first-line all-oral versus taxane-based chemotherapy for HER2-negative metastatic breast cancer. Clin Breast Cancer 2017(17):91-99

4. Lorusso $\mathrm{V}$ et al (2010) Intravenous versus oral vinorelbine plus capecitabine as second-line treatment in advanced breast cancer patients. A retrospective comparison of two consecutive phase II studies. Breast 19:214-218

Publisher's Note Springer Nature remains neutral with regard to jurisdictional claims in published maps and institutional affiliations. 